\title{
Blunted perception of neural respiratory drive and breathlessness in patients with cystic fibrosis
}

\author{
Charles C. Reilly ${ }^{1,2}$, Caroline J. Jolley ${ }^{1}$, Caroline Elston ${ }^{3}$, John Moxham ${ }^{1}$ and \\ Gerrard F. Rafferty ${ }^{1}$
}

Affiliations: 'King's College London, Faculty of Life Sciences and Medicine, London, UK. ${ }^{2}$ King's College Hospital, Physiotherapy, London, UK. ${ }^{3}$ King's College Hospital, Respiratory Medicine, London, UK.

Correspondence: Charles C. Reilly, King's College London, Division of Asthma Allergy and Lung Biology, Dept of Asthma, Allergy and Respiratory Science, Bessemer Road, London SE5 9PJ, UK.

E-mail: charles.c.reillyakcl.ac.uk

ABSTRACT The electromyogram recorded from the diaphragm (EMGdi) and parasternal intercostal muscle using surface electrodes (sEMGpara) provides a measure of neural respiratory drive (NRD), the magnitude of which reflects lung disease severity in stable cystic fibrosis. The aim of this study was to explore perception of NRD and breathlessness in both healthy individuals and patients with cystic fibrosis. Given chronic respiratory loading and increased NRD in cystic fibrosis, often in the absence of breathlessness at rest, we hypothesised that patients with cystic fibrosis would be able to tolerate higher levels of NRD for a given level of breathlessness compared to healthy individuals during exercise.

15 cystic fibrosis patients (mean forced expiratory volume in $1 \mathrm{~s}$ (FEV1) 53.5\% predicted) and 15 agematched, healthy controls were studied. Spirometry was measured in all subjects and lung volumes measured in the cystic fibrosis patients. EMGdi and sEMGpara were recorded at rest and during incremental cycle exercise to exhaustion and expressed as a percentage of maximum (\% max) obtained from maximum respiratory manoeuvres. Borg breathlessness scores were recorded at rest and during each minute of exercise.

EMGdi \% max and sEMGpara \% max and associated Borg breathlessness scores differed significantly between healthy subjects and cystic fibrosis patients at rest and during exercise. The relationship between EMGdi \% max and sEMGpara \% max and Borg score was shifted to the right in the cystic fibrosis patients, such that at comparable levels of EMGdi \% max and sEMGpara \% max the cystic fibrosis patients reported significantly lower Borg breathlessness scores compared to the healthy individuals. At Borg score 1 (clinically significant increase in breathlessness from baseline) corresponding levels of EMGdi \% max $(20.2 \pm 12 \%$ versus $32.15 \pm 15 \%, \mathrm{p}=0.02)$ and $\mathrm{sEMG}$ ara $\% \max (18.9 \pm 8 \%$ versus $29.2 \pm 15 \%, \mathrm{p}=0.04)$ were lower in the healthy individuals compared to the cystic fibrosis patients.

In the cystic fibrosis patients EMGdi \% max at Borg score 1 was related to the degree of airways obstruction $(\mathrm{FEV})(\mathrm{r}=-0.664, \mathrm{p}=0.007)$ and hyperinflation (residual volume/total lung capacity) $(\mathrm{r}=0.710$, $\mathrm{p}=0.03$ ). This relationship was not observed for $\mathrm{sEMGpara} \% \max$.

These data suggest that compared to healthy individuals, patients with cystic fibrosis can tolerate much higher levels of NRD before increases in breathlessness from baseline become clinically significant. EMGdi $\%$ max and sEMGpara \% max provide physiological tools with which to elucidate factors underlying interindividual differences in breathlessness perception.

@ERSpublications

Patients with CF can tolerate higher levels of NRD before breathlessness becomes clinically significant http://ow.ly/Xp2q3

Received: Aug 172015 | Accepted after revision: Jan 172016

Support statement: Charles C. Reilly was supported by a Medical Research Council (London, UK) PhD studentship. Funding information for this article has been deposited with FundRef.

Conflict of interest: None declared.

Copyright OERS 2016. The content of this work is @ the authors or their employers. Design and branding are OERS 2016. This article is open access and distributed under the terms of the Creative Commons Attribution Non-Commercial Licence 4.0 . 


\section{Introduction}

Cystic fibrosis is characterised by a chronic progressive and irreversible loss of pulmonary function, with the main cause of death being respiratory failure. A dominant clinical feature of cystic fibrosis is airways obstruction, precipitated by abnormal mucus production and the persistent negative cycle of airway infection and inflammation [1]. In cystic fibrosis there is both an increased load on the respiratory system and a reduction in ventilatory capacity.

Physiological abnormalities associated with cystic fibrosis include increased airway resistance and altered chest wall and respiratory muscle geometry as a consequence of hyperinflation $[2,3]$. We have previously demonstrated that the electromyogram (EMG) of the diaphragm (EMGdi) and the parasternal intercostal muscles using surface electrodes (sEMGpara) expressed as a percentage of maximum (\% max) provide sensitive real-time breath-by-breath measures of neural respiratory drive (NRD) which reflect the load on, and the capacity of, the respiratory muscle pump, and hence disease severity in cystic fibrosis [4].

Increasing breathlessness is a common manifestation of lung disease progression and a limiting factor to exercise in cystic fibrosis. Standard spirometric measurements, such as forced expiratory volume in $1 \mathrm{~s}$ (FEV1) are poorly correlated with breathlessness in cystic fibrosis. Recently, we [4] and others [5-9] have demonstrated the relationship between increasing levels of breathlessness during exercise and concurrent increases in central NRD. Furthermore, we have shown that EMGdi \% max and sEMGpara \% max provide a physiological correlate to exercise-induced breathlessness in patients with cystic fibrosis, before and after the onset of neuromechanical dissociation [4]. More recently, Jolley et al. [10] reported the relationship between NRD, neuroventilatory uncoupling and breathlessness, demonstrating that during exercise an increased awareness of NRD was more closely related to breathlessness intensity than neuroventilatory uncoupling and other ventilatory variables in patients with chronic obstructive pulmonary disease (COPD). Moreover, GrønseTh et al. [11] reported that only 13\% of the variation in reported breathlessness can be explained by demographics and lung function variables. Less is known about the relationship between NRD and the perception/sensation of breathlessness at an individual level in healthy individuals compared to patients with respiratory disease.

The aim of this study was to explore perception of NRD and breathlessness in both healthy individuals and patients with cystic fibrosis. Given chronic respiratory loading and increased NRD in cystic fibrosis, often in the absence of breathlessness at rest, we hypothesised that patients with cystic fibrosis would be able to tolerate higher levels of NRD for a given level of breathlessness compared to healthy individuals during exercise.

\section{Methods}

Secondary analysis of data previously reported by ReILLY et al. [4] was performed.

\section{Subjects}

The original study involved healthy adult subjects and clinically stable cystic fibrosis patients. The study was approved by the King's College Hospital (London, UK) ethics committee and all participants provided written informed consent.

\section{Pulmonary function}

Spirometry (FEV1 and slow vital capacity) was performed in all subjects [12] (Vitalograph Gold Standard; Vitalograph Ltd. Buckingham, UK). Peak expiratory flow and total lung capacity (TLC) and residual volume (RV) were measured using body plethysmography [13] (Masterscreen Body Box; Jaeger, Frieburg, Germany) in the cystic fibrosis patients.

\section{Electromyographic measurements}

EMGdi and sEMGpara were recorded at rest and during exercise in all subjects. EMGdi was recorded from the crural diaphragm using a multipair oesophageal electrode catheter, consisting of nine consecutive coils forming five recording electrode pairs [14]. sEMGpara was recorded using bipolar surface electrodes (Kendall Arbo, Tyco Healthcare, Neustadt, Germany) placed bilaterally $3 \mathrm{~cm}$ from the midpoint of the sternum in the second intercostal space. The positive electrode was placed on the right side of the chest and the reference electrode on the lateral aspect of the right clavicle $[4,15,16]$.

The EMG signals were amplified and bandpass filtered between $10 \mathrm{~Hz}$ and $3 \mathrm{kHz}$ (RA-8 biomedical amplifier; Yinghui Medical Tech Ltd, Guangzhou, China) and acquired and displayed on a laptop computer (MacBook; Apple Computer Corp, Cupertino, CA, USA) running Chart version 5.4 software (ADInstruments, Colorado Springs, CO, USA) with analogue-to-digital sampling at $2 \mathrm{kHz}$ (Powerlab; ADInstruments). Post-acquisition bandpass filtering between $20 \mathrm{~Hz}$ and $1 \mathrm{kHz}$ was applied to all recordings using the acquisition software. Peak root mean square per breath was calculated and averaged over a 
minute. EMG recordings at rest and during exercise were normalised to the EMG signal obtained during a maximal volitional manoeuvre. Four different maximal volitional manoeuvres were performed: inspiratory capacity, maximal static inspiratory pressure, maximal sniff pressure and maximal voluntary ventilation for $15 \mathrm{~s}[4,14]$. Each manoeuvre was repeated five times and irrespective of manoeuvre, the numerically largest EMG signal was used for normalisation $[4,17]$.

\section{Study protocol}

Patients were advised to continue with their normal daily regimen with regards to both medications and physiotherapy; however, if they were routinely using a short-acting $\beta_{2}$-agonist they were asked to withhold this for $\geqslant 4 \mathrm{~h}$ prior to their visit.

On the day of testing, spirometry [18] was measured in all subjects and lung volumes were measured in the cystic fibrosis patients. The diaphragm EMG catheter was inserted and positioned as previously described [4]. EMGdi and sEMGpara were measured at rest, during the standardised maximal spontaneous volitional manoeuvres and during an incremental exercise test.

Subjects performed an incremental cycle exercise test to exhaustion on an electrically braked cycle ergometer. Work rate was increased by $25 \mathrm{~W}$ in the cystic fibrosis patients and $50 \mathrm{~W}$ in the healthy subjects every $3 \mathrm{~min}$, starting with unloaded cycling. Subjects maintained 50-60 revolutions per minute. Exercise-induced breathlessness was measured using the modified Borg scale, recorded at the end of each minute of the incremental exercise test. Prior to the exercise test all participants were briefed on the modified Borg scale by explaining that the descriptors of breathlessness intensity on the modified Borg scale are anchored to numerical points on the scale, e.g. $0=$ no breathlessness and $10=$ maximum breathlessness that the participant had ever experienced [19].

\section{Data analysis}

All data except Borg scores were normally distributed and expressed as mean \pm sD. Borg scores are expressed as median (interquartile range). As the Borg breathlessness scores are categorical, a logarithmic transformation was applied to these data to allow for comparison between EMGdi \% max and sEMGpara \% max for a given level of breathlessness [20].

The minimal clinically important difference (MCID) of the Borg scale is 1; therefore, we used the point at which breathlessness was more than the MCID above baseline, which was Borg score 1 for both groups, as a clinically significant increase in breathlessness. t-tests were used to compare EMGdi \% max and sEMGpara \% max at a Borg score of 1 , between the healthy individuals and patients. Pearson's correlation analysis was used to investigate the association between each individual's levels of EMGdi and sEMGpara for a Borg score of 1 and lung function.

Statistical analysis of the data was performed using GraphPad Prism (version 5.02 for Windows; GraphPad Software, San Diego, CA, USA).

\section{Results}

15 patients (mean \pm SD age $24 \pm 5.5$ years) with cystic fibrosis (FEV1 $53.5 \pm 24 \%$ predicted) and 15 healthy subjects (age $25 \pm 3$ years) were studied. The anthropometric characteristics and pulmonary function for both the healthy subjects and cystic fibrosis patients are summarised in table 1.

EMGdi \% max and sEMGpara \% max measured during resting tidal breathing was higher in the cystic fibrosis patients compared to the healthy individuals. However, end-exercise EMGdi \% max and sEMGpara $\%$ max were similar in both groups (table 2).

Borg breathlessness scores and associated levels of EMGdi \% max and sEMGpara \% max were different between the healthy subjects and the cystic fibrosis patients during exercise. At comparable levels of EMGdi \% max and sEMGpara \% max the cystic fibrosis patients reported significantly lower Borg breathlessness scores compared to the healthy individuals (fig. 1). At the point of breathlessness onset (Borg score 1) corresponding levels of EMGdi \% max and sEMGpara \% max were lower in the healthy individuals compared to the cystic fibrosis patients (table 2).

In the cystic fibrosis patients EMGdi \% max at the onset of breathlessness was related to the degree of airways obstruction $(\mathrm{FEV} 1)(\mathrm{r}=-0.664, \mathrm{p}=0.007)$ and hyperinflation (RV/TLC) $(\mathrm{r}=0.710, \mathrm{p}=0.03)$. This relationship was not observed in the sEMGpara \% max (table 3, figs 2 and 3).

\section{Discussion}

The main finding of this secondary data analysis reinforces and builds upon the observations of JolLEY et al. [10] in patients with COPD. We observed that the relationship between exercise-induced Borg 
TABLE 1 Anthropometric characteristics and pulmonary function variables for healthy subjects and patients with cystic fibrosis

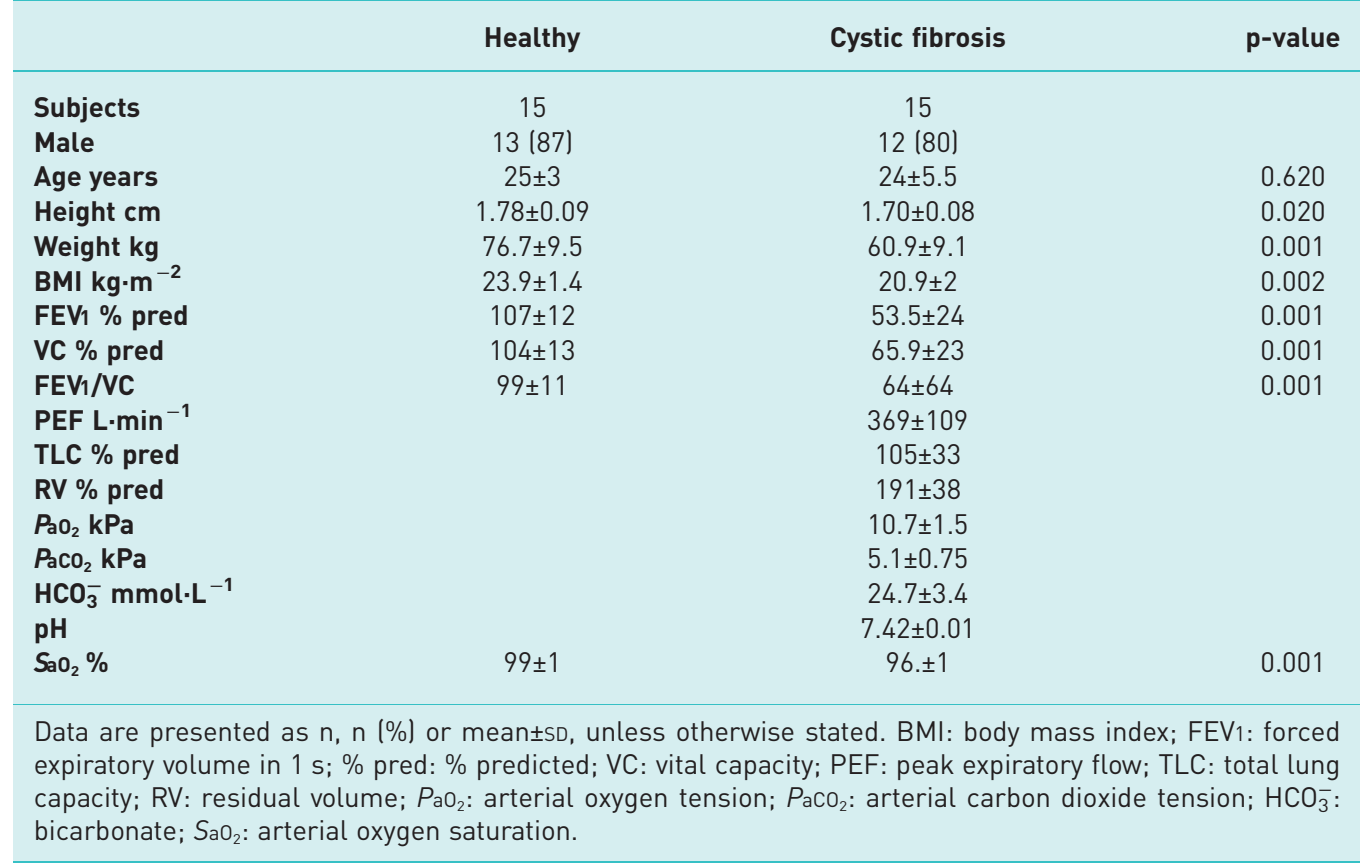

breathlessness scores and levels of NRD were different between healthy subjects and cystic fibrosis patients. The relationship in the cystic fibrosis patients was shifted to the right, such that at comparable levels of EMGdi \% max and sEMGpara \% max, cystic fibrosis patients reported lower Borg breathlessness scores compared to healthy individuals. Such a shift could suggest that the cystic fibrosis patients were habituated or desensitised to the chronically increased respiratory load imposed by their disease.

\section{Significance of the findings}

The respiratory muscles of patients with cystic fibrosis are subject to an increased resistive load due to airways obstruction. Hyperinflation as a consequence of gas trapping places these patients on the upper flattened portion of the lung and chest wall compliance curve, increasing the elastic work of breathing, while the development of intrinsic positive end-expiratory pressure imposes a threshold load that needs to be overcome with each breath [2]. The altered chest wall geometry that occurs as a result of lung hyperinflation reduces the force-generating capacity of the inspiratory muscles and their effectiveness at

TABLE 2 Levels of neural respiratory drive at rest, at Borg score 1 and end-exercise in healthy individuals and patients with cystic fibrosis

\begin{tabular}{|c|c|c|c|}
\hline & Healthy & Cystic fibrosis & p-value \\
\hline \multicolumn{4}{|l|}{ Rest } \\
\hline EMGdi $\% \max$ & $7.5 \pm 2$ & $18.5 \pm 7.5$ & 0.001 \\
\hline sEMGpara \% max & $5.8 \pm 3$ & $13.1 \pm 7$ & 0.001 \\
\hline \multicolumn{4}{|l|}{ Breathlessness threshold } \\
\hline EMGdi $\% \max$ & $20.2 \pm 12$ & $32.1 \pm 15$ & 0.024 \\
\hline sEMGpara \% max & $18.9 \pm 8$ & $29.2 \pm 15$ & 0.040 \\
\hline \multicolumn{4}{|l|}{ End-exercise } \\
\hline EMGdi $\% \max$ & $75 \pm 18.5$ & $71.2 \pm 5$ & 0.550 \\
\hline sEMGpara $\% \max$ & $48.6 \pm 20$ & $55.3 \pm 27$ & 0.440 \\
\hline Borg breathlessness score & $8(7-9)$ & $7(6-9)$ & 0.690 \\
\hline \multicolumn{4}{|c|}{$\begin{array}{l}\text { Data are presented as mean } \pm S D \text { or median (interquartile range), unless otherwise stated. EMGdi: } \\
\text { electromyogram recorded from the diaphragm; } \% \text { max: } \% \text { of maximum; sEMGpara: electromyogram } \\
\text { recorded using surface electrodes from the parasternal intercostal muscle. }\end{array}$} \\
\hline
\end{tabular}



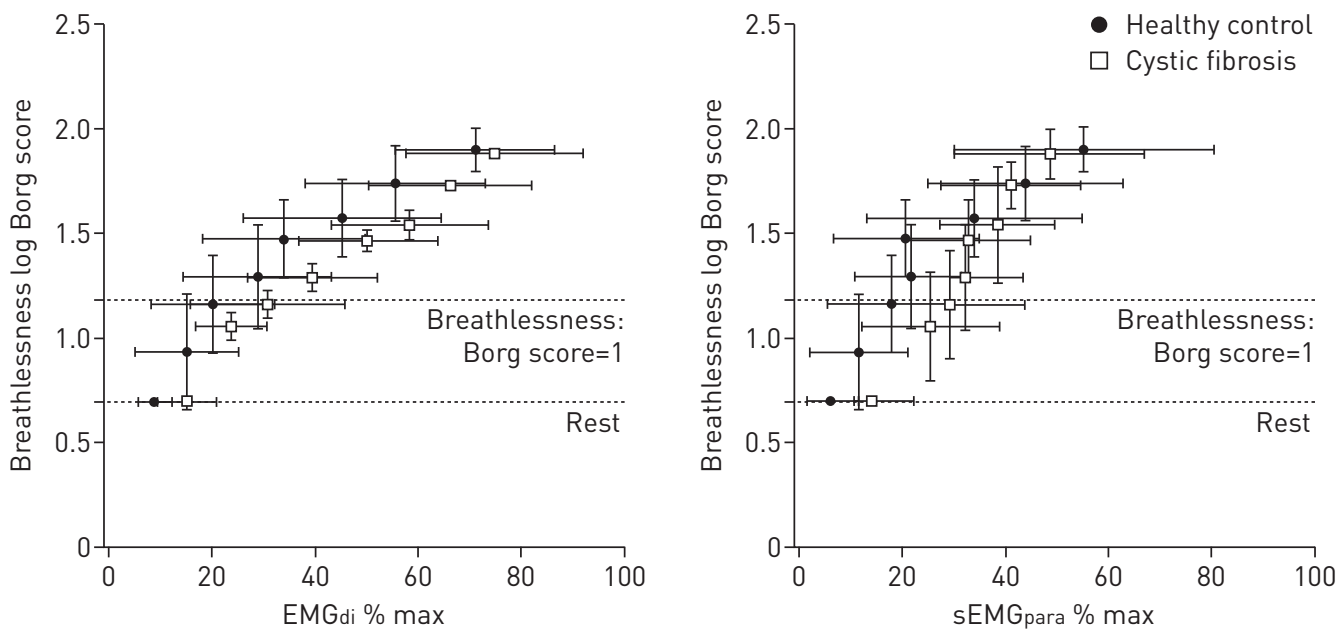

FIGURE 1 The relationship between neural respiratory drive and breathlessness perception during incremental exercise in healthy individuals and patients with cystic fibrosis. EMGdi: electromyogram recorded from the diaphragm; \% max: \% of maximum; SEMGpara: electromyogram recorded using surface electrodes from the parasternal intercostal muscle.

lowering intrathoracic pressure, which is further reduced during exercise [21]. The increased respiratory load, and reduced inspiratory muscle capacity in cystic fibrosis patients is reflected by increased levels of EMGdi \% max and sEMGpara \% max compared to healthy individuals [4].

Repeated experience of a stimulus can lead to a gradual reduction of response amplitude to that stimulus (habituation), with both an increased threshold for response generation and a decreased sensitivity to the stimulus contributing to this effect $[22,23]$. Habituation has been demonstrated for many different types of stimuli, such as pain [24] and perceived breathlessness following repeated carbon dioxide rebreathing in healthy individuals $[23,25]$. Habituation has also been observed as an adaptive physiological response to chronic hypertension resulting in central baroreflex resetting [26].

Our data are in keeping with JolLEY et al. [10], who demonstrated that the intensity of exertional breathlessness is closely related to NRD, and that breathlessness can be largely explained by an increased awareness of the levels of NRD, rather than neuroventialtory uncoupling. In response to HUDSON and LAVENEZIANA [27], our data confirm that in cystic fibrosis NRD to obligatory muscles, i.e. the parasternal intercostal muscles (sEMGpara) is correlated to dyspnoea sensation. In addition, this study demonstrates that compared to healthy individuals, patients with cystic fibrosis have a reduced conscious awareness of NRD and can tolerate high levels of NRD for a given level of breathlessness, suggesting that the patients have become habituated to increased NRD as a consequence of their lung disease. Recent work by GuenetTe et al. [28], comparing mild COPD patients with healthy individuals, did not demonstrate this shift to the right, which supports our hypothesis, as these patients had very mild disease.

TABLE 3 The relationship between diaphragm electromyogram (EMGdi) \% of maximum (\% max) and parasternal intercostal muscle electromyogram measured using surface electrodes (sEMGpara) \% max at Borg score 1 during exercise and resting lung function, measured in 15 patients with cystic fibrosis

EMGdi \% max

sEMGpara \% max

\begin{tabular}{lcccc} 
& Pearson's correlation $\mathbf{r}$ & p-value & Pearson's correlation $\mathbf{r}$ & p-value \\
\hline FEV1 \% pred & -0.664 & 0.007 & 0.212 & 0.449 \\
VC \% pred & -0.672 & 0.006 & 0.130 & 0.643 \\
FEV1/VC & -0.423 & 0.115 & 0.334 & 0.223 \\
TLC \% pred & 0.271 & 0.323 & 0.343 & 0.211 \\
RV \% pred & 0.493 & 0.062 & -0.055 & 0.470 \\
RV/TLC & 0.710 & 0.003 & -0.102 & 0.71
\end{tabular}

FEV1: forced expiratory volume in $1 \mathrm{~s}$; \% pred: \% predicted; VC: vital capacity; TLC: total lung capacity; RV: residual volume. 

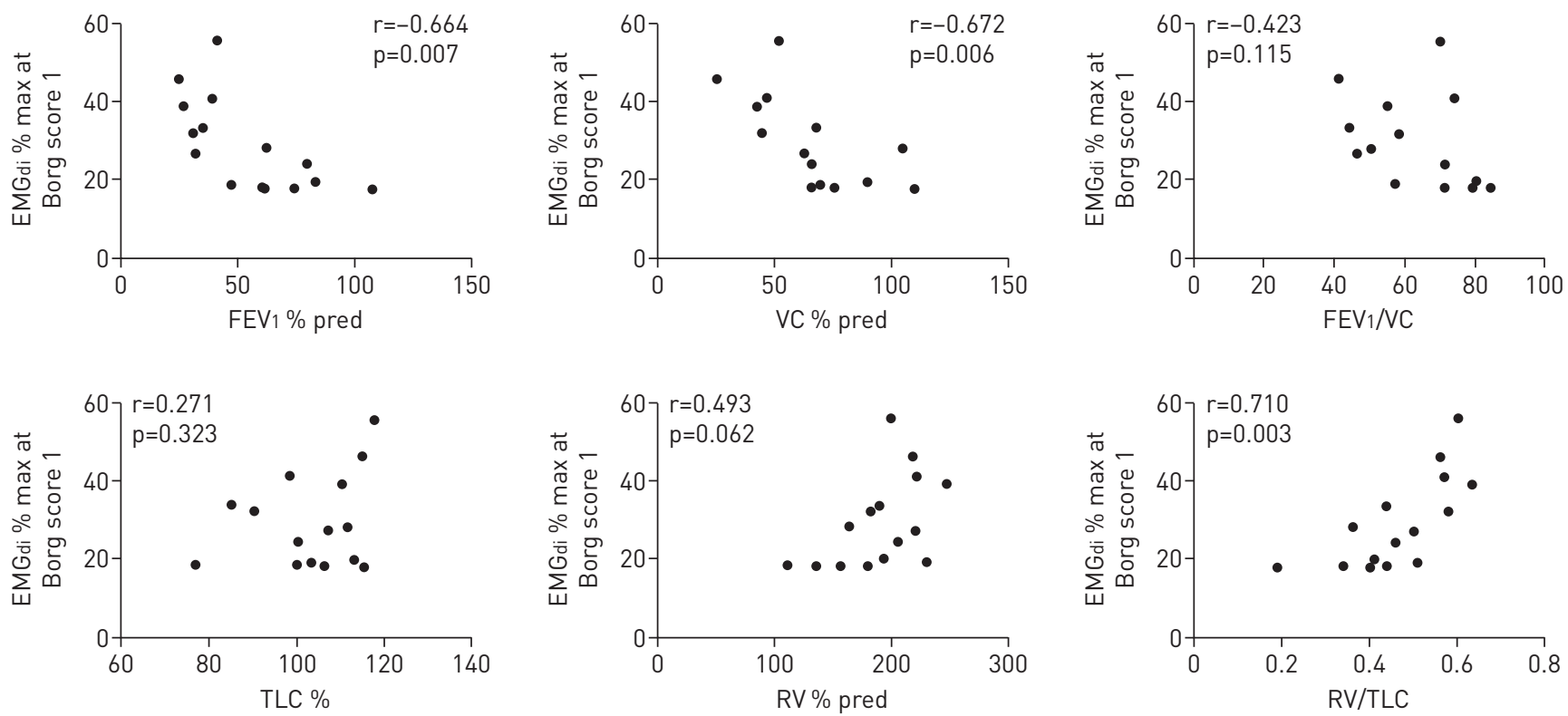

FIGURE 2 The relationship between electromyogram recorded from the diaphragm (EMGdi) expressed as a percentage of maximum (\% max) at the breathlessness threshold (Borg score 1) during exercise and resting lung function, measured in 15 patients with cystic fibrosis. FEV1: forced expiratory volume in $1 \mathrm{~s}$; \% pred: \% predicted; VC: vital capacity; TLC: total lung capacity; RV: residual volume.

Previous investigators have reported that breathlessness perception in asthmatic patients shows considerable variation, but no correlation to lung function measures [29, 30]. Moreover, a reduced perception of breathlessness in asthmatic patients is associated with an increased risk of mortality [29, 30]. The blunted perception of breathlessness in this patient group may have occurred as a consequence of habituation, as studies using respiratory evoked potentials have demonstrated reduced neural processing of breathlessness signals in patients with chronic respiratory disease [31-33]. This phenomenon has been suggested as a mechanism to explain improved breathlessness during pulmonary rehabilitation.
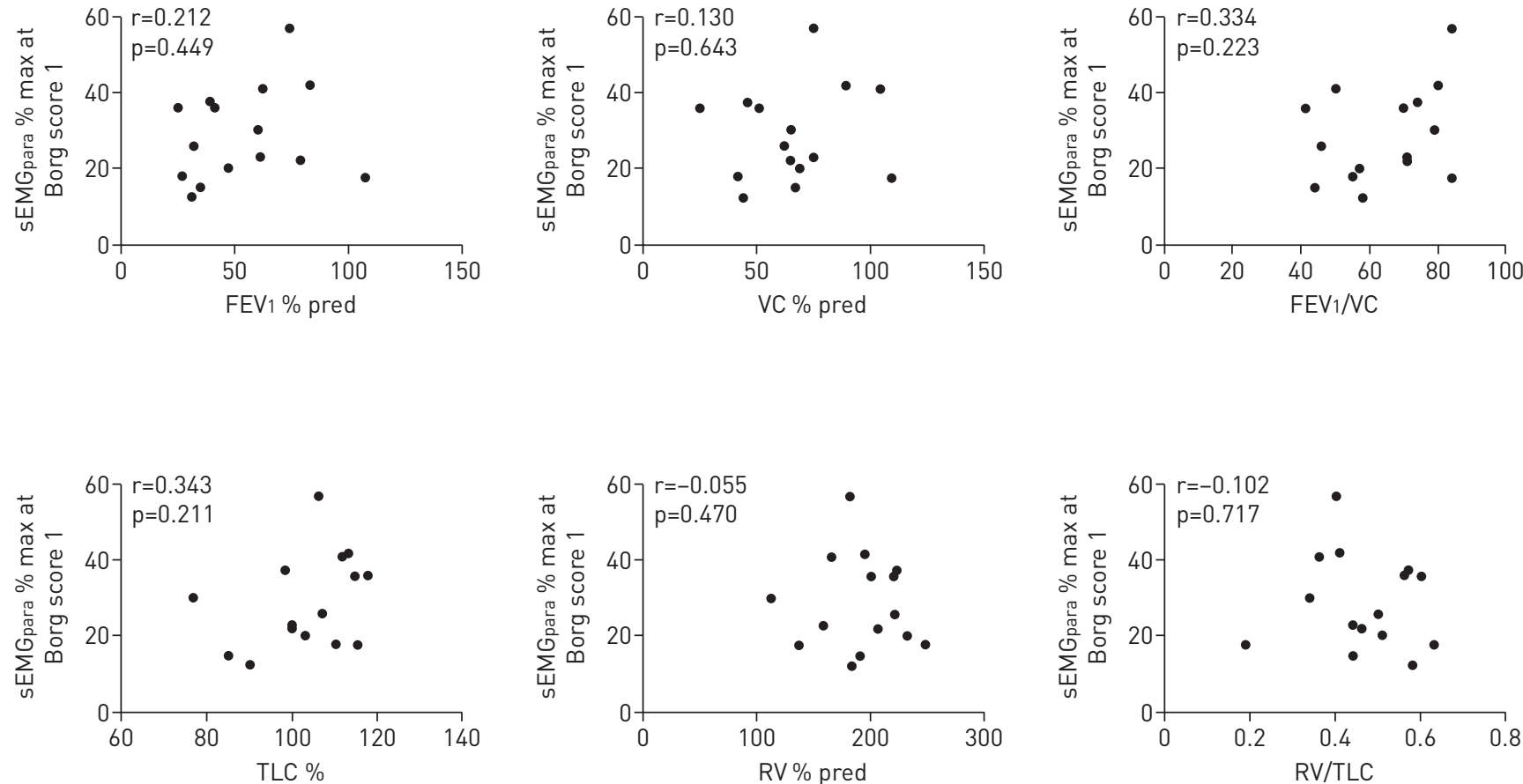

FIGURE 3 The relationship between electromyogram recorded from the parasternal intercostal muscles using surface electrodes (sEMGpara) expressed as a percentage of maximum (\% max) at the breathlessness threshold (Borg score 1) during exercise and resting lung function, measured in 15 patients with cystic fibrosis. FEV1: forced expiratory volume in 1 s; \% pred: \% predicted; VC: vital capacity; TLC: total lung capacity; RV: residual volume. 
In addition, functional magnetic resonance imaging studies have shown that reduced perception of breathlessness is associated with reduced insular cortex activation and increased periaqueductal grey (PAG) grey matter volume in asthmatic patients. Changes in these brain structures were related to illness duration [34]. The insular cortex is an important multisensory integration area involved in the processing of various unpleasant bodily signals and emotions, while the PAG plays an important role in the up- and downregulation of pain sensations [34]. VON LEUPOLDT et al. [34] attributed these structural and perceptional adaptions to neural habituation to repeated breathlessness experiences, similar to that reported to occur in chronic pain $[35,36]$.

Despite EMGdi \% max and sEMGpara \% max being higher in the cystic fibrosis patients at Borg score 1, only EMGdi \% max was proportional to the degree of airways obstruction (FEV1) and hyperinflation (RV/ TLC). This may be explained by differential recruitment patterns and potential neuroventilatory uncoupling [10]. GANDEvia et al. [37] demonstrated that the parasternal intercostal muscles and the diaphragm adopt different "strategies" to increase motor unit output when NRD increases; the diaphragm showing a predominance for frequency modulation, and the parasternal intercostal muscles a predominance for motor unit recruitment. In addition, diaphragm activation approaching the upper limit of ventilatory capacity appears to be closer to maximum than that of the parasternal intercostal muscles under the same condition $[4,10,38]$. Hyperinflation-associated muscle shortening is also considerably less in the parasternal intercostal muscles [39] compared to the diaphragm and so the extent of neuroventilatory uncoupling can be expected to be greater in the diaphragm than in the parasternal intercostal muscles $[10,40]$, which may partly explain this observation.

\section{Critique of the method}

NRD measured by EMGdi obtained using an oesophageal catheter is a sensitive and reproducible method for quantifying NRD in both healthy subjects and patients $[4,5,7,13]$. However, the technique is invasive, which limits its application clinically. Quantifying NRD using sEMGpara recordings provides similar information to that obtained from oesophageal EMGdi, with the advantage of being noninvasive and therefore more clinically applicable.

Surface EMG recordings often have poor inter-subject and inter-occasion reproducibility, due to variations in electrical contact and electrode position relative to the underlying muscle. We have previously demonstrated reproducible inter-occasion parasternal EMG signals measured during resting tidal breathing, with a mean inter-occasion coefficient of variation of $0.05 \pm 0.04 \mu \mathrm{V}$ in healthy individuals [16]. Using Bland-Altman analysis MAARSINGH et al. [16] reported good reproducibility of sEMGpara measured during resting tidal breathing in young adults and both healthy and asthmatic school children. They reported a mean difference of $\leqslant 1 \mu \mathrm{V}$ for all the groups. In addition, Murphy et al. [41] demonstrated reproducible sEMGpara measurements in patients with stable COPD at rest, with a mean difference of $1.26 \pm 2.45 \mu \mathrm{V}$ in EMG values between occasions.

When interpreting these results some limitations need to be acknowledged. We studied patients with predominantly moderate cystic fibrosis lung disease; future studies would benefit from a larger sample of patients drawn from the entire disease spectrum to allow the relationship between disease severity, NRD, breathlessness perception and habituation to be explored more fully. Additional data beyond FEV1, that reflect the progression of cystic fibrosis lung disease, such as exacerbation frequency and hospitalisations may also be useful to understand the mechanisms of breathlessness perception and habituation.

Only breathlessness intensity was measured, without reference to breathlessness descriptors or affective components; these additional measures may have provided useful additional information regarding the relationship between individual experiences of breathlessness and NRD perception [42].

\section{Conclusion}

These data suggest that compared to healthy individuals, patients with cystic fibrosis can tolerate much higher levels of NRD before increases in breathlessness from baseline become clinically significant. EMGdi $\% \max$ and sEMGpara \% max provide physiological tools with which to elucidate factors underlying inter-individual differences in breathlessness perception.

\section{References}

1 Sheppard MN, Nicholson AG. The pathology of cystic fibrosis. Curr Diagn Pathol 2002; 8: 50-59.

2 Hart N, Polkey MI, Clément A, et al. Changes in pulmonary mechanics with increasing disease severity in children and young adults with cystic fibrosis. Am J Respir Crit Care Med 2002; 166: 61-66.

3 Regnis J, Donnelly P, Robinson M, et al. Ventilatory mechanics at rest and during exercise in patients with cystic fibrosis. Am J Respir Crit Care Med 1996; 154: 1418-1425.

4 Reilly CC, Ward K, Jolley CJ, et al. Neural respiratory drive, pulmonary mechanics and breathlessness in patients with cystic fibrosis. Thorax 2011; 66: 240-246. 
5 Jensen D, O'Donnell DE, Li R, et al. Effects of dead space loading on neuro-muscular and neuro-ventilatory coupling of the respiratory system during exercise in healthy adults: implications for dyspnea and exercise tolerance. Respir Physiol Neurobiol 2011; 179: 219-226.

6 Xiao SC, Lu YR, Guo HX, et al. Effect of expiratory load on neural inspiratory drive. Chin Med J 2012; 125 3629-3634.

7 Luo YM, Li RF, Jolley C, et al. Neural respiratory drive in patients with COPD during exercise tests. Respiration 2011; 81: 294-301.

8 O'Donnell DE, Banzett RB, Carrieri-Kohlman V, et al. Pathophysiology of dyspnea in chronic obstructive pulmonary disease: a roundtable. Proc Am Thorac Soc 2007; 4: 145-168.

9 Qin YY, Steier J, Jolley C, et al. Efficiency of neural drive during exercise in patients with COPD and healthy subjects. Chest 2010; 138: 1309-1315.

10 Jolley CJ, Luo YM, Steier J, et al. Neural respiratory drive and breathlessness in COPD. Eur Respir J 2015; 45: 355-364.

11 Grønseth R, Vollmer WM, Hardie JA, et al. Predictors of dyspnoea prevalence: results from the BOLD study Eur Respir J 2014; 43: 1610-1620.

12 Miller MR, Hankinson J, Brusasco V, et al. Standardisation of spirometry. Eur Respir J 2005; 26: 319-338.

13 Wanger J, Clausen JL, Coates A, et al. Standardisation of the measurement of lung volumes. Eur Respir J 2005; 26: 511-522.

14 Jolley CJ, Luo Y-M, Steier J, et al. Neural respiratory drive in healthy subjects and in COPD. Eur Respir J 2009; 33 289-297.

15 Duiverman ML, van Eykern LA, Vennik PW, et al. Reproducibility and responsiveness of a noninvasive EMG technique of the respiratory muscles in COPD patients and in healthy subjects. J Appl Physiol 2004; 96: 1723-1729.

16 Maarsingh EJ, van Eykern LA, Sprikkelman AB, et al. Respiratory muscle activity measured with a noninvasive EMG technique: technical aspects and reproducibility. I Appl Physiol 2000; 88: 1955-1961.

17 Reilly CC, Ward K, Jolley CJ, et al. Neural respiratory drive, pulmonary mechanics and breathlessness in patients with cystic fibrosis. Thorax 2011; 66: 240-246.

18 Hutchison AA, Wozniak JA, Choi HG, et al. Respiratory muscle activities after birth in asphyxiated preterm lambs. Acta Paediatr 1994; 83: 241-248.

19 Mador MJ, Rodis A, Magalang UJ. Reproducibility of Borg scale measurements of dyspnea during exercise in patients with COPD. Chest 1995; 107: 1590-1597.

20 Martínez Francés ME, Perpiñá Tordera M, Belloch Fuster A, et al. ¿Cómo valorar la percepción de la disnea inducida en la EPOC? [How can we assess the perception of induced dyspnea in chronic obstructive pulmonary disease?]. Arch Bronconeumol 2004; 40: 149-154.

21 Polkey MI, Kyroussis D, Hamnegard CH, et al. Diaphragm strength in chronic obstructive pulmonary disease. Am J Respir Crit Care Med 1996; 154: 1310-1317.

22 Rodriguez-Raecke R, Ihle K, Ritter C, et al. Neuronal differences between chronic low back pain and depression regarding long-term habituation to pain. Eur J Pain 2014; 18: 701-711.

23 Wan L, Van Diest I, De Peuter S, et al. Repeated breathlessness experiences induced by hypercapnia: differential effects on intensity and unpleasantness. Chest 2009; 135: 455-461.

24 Crombez G, Vervaet L, Baeyens F, et al. Do pain expectancies cause pain in chronic low back patients? A clinical investigation. Behav Res Ther 1996; 34: 919-925.

25 Wan L, Van Diest I, De Peuter S, et al. Repeated experiences of air hunger and ventilatory behavior in response to hypercapnia in the standardized rebreathing test: effects of anxiety. Biol Psychol 2008; 77: 223-232.

26 Chapleau MW, Hajduczok G, Abboud FM. Peripheral and central mechanisms of baroreflex resetting. Clin Exp Pharmacol Physiol Suppl 1989; 15: 31-43.

27 Hudson AL, Laveneziana P. Do we "drive" dyspnoea? Eur Respir J 2015; 45: 301-304.

28 Guenette JA, Chin RC, Cheng S, et al. Mechanisms of exercise intolerance in Global Initiative for Chronic Obstructive Lung Disease grade 1 COPD. Eur Respir J 2014; 44: 1177-1187.

29 Barnes PJ. Blunted perception and death from asthma. N Engl J Med 1994; 330: 1383-1384

30 Feldman JM, McQuaid EL, Klein RB, et al. Symptom perception and functional morbidity across a 1-year follow-up in pediatric asthma. Pediatr Pulmonol 2007; 42: 339-347.

31 von Leupoldt A, Vovk A, Bradley MM, et al. Habituation in neural processing and subjective perception of respiratory sensations. Psychophysiology 2011; 48: 808-812.

32 Davenport PW, Cruz M, Stecenko AA, et al. Respiratory-related evoked potentials in children with life-threatening asthma. Am J Respir Crit Care Med 2000; 161: 1830-1835.

33 Fauroux B, Renault F, Boelle PY, et al. Impaired cortical processing of inspiratory loads in children with chronic respiratory defects. Respir Res 2007; 8: 61

34 von Leupoldt A, Brassen S, Baumann HJ, et al. Structural brain changes related to disease duration in patients with asthma. PloS One 2011; 6: e23739.

35 Geha PY, Baliki MN, Harden RN, et al. The brain in chronic CRPS pain: abnormal gray-white matter interactions in emotional and autonomic regions. Neuron 2008; 60: 570-581.

36 May A. Chronic pain may change the structure of the brain. Pain 2008; 137: 7-15

37 Gandevia SC, Gorman RB, McKenzie DK, et al. Effects of increased ventilatory drive on motor unit firing rates in human inspiratory muscles. Am J Respir Crit Care Med 1999; 160: 1598-1603.

38 Reilly CC, Jolley CJ, Ward K, et al. Neural respiratory drive measured during inspiratory threshold loading and acute hypercapnia in healthy individuals. Exp Physiol 2013; 98: 1190-1198.

39 Decramer M, De Troyer A. Respiratory changes in parasternal intercostal length. J Appl Physiol Respir Environ Exerc Physiol 1984; 57: 1254-1260.

40 Decramer M, Xi JT, Reid MB, et al. Relationship between diaphragm length and abdominal dimensions. J Appl Physiol 1986; 61: 1815-1820.

41 Murphy PB, Kumar A, Reilly C, et al. Neural respiratory drive as a physiological biomarker to monitor change during acute exacerbations of COPD. Thorax 2011; 66: 602-608.

42 Laviolette L, Laveneziana P. Dyspnoea: a multidimensional and multidisciplinary approach. Eur Respir J 2014; 43: $1750-1762$. 